\title{
Still Fighting for Breath: a patient survey of the challenges and impact of severe asthma
}

\author{
Paraskevi Katsaounou (1) ${ }^{1}$, Mikaela Odemyr², Otto Spranger ${ }^{3}$, \\ Michael E. Hyland ${ }^{4}$, Claus Kroegel ${ }^{5}$, Lorena Garcia Conde ${ }^{6}$, \\ Robin Gore ${ }^{7}$, Francesco Menzella $\mathbb{0}^{8}$, Christian Domingo Ribas ${ }^{9}$, \\ Mario Morais-Almeida ${ }^{10}$, Matthias Gasser ${ }^{11}$ and Ismail Kasujee ${ }^{6}$
}

Affiliations: ${ }^{1}$ First ICU Evaggelismos Hospital, National and Kapodistrian University of Athens, Athens, Greece. ${ }^{2}$ European Federation of Allergy and Airways Diseases Patients' Associations, Brussels, Belgium. ${ }^{3}$ Global Allergy and Asthma Patient Platform, Vienna, Austria. ${ }^{4}$ School of Psychology, University of Plymouth, Plymouth, UK. ${ }^{5}$ Dept of Pneumology and Allergy/lmmunology, Medical University Hospital Jena, Jena, Germany. ${ }^{6}$ Novartis Pharma AG, Basel, Switzerland. ${ }^{7}$ Addenbrookes Hospital, Cambridge University Hospitals NHS Foundation Trust, Cambridge, UK. ${ }^{8}$ Specialist Medicine Dept, Pneumology Unit, Arcispedale Santa Maria Nuova, Reggio Emilia, Italy. ${ }^{9}$ Pulmonary Service, Corporació Sanitària Parc Taulí (Sabadell), Dept of Medicine, Universitat Autònoma de Barcelona (UAB), Barcelona, Spain. ${ }^{10}$ Allergy Center, CUF Descobertas Hospital, Lisbon, Portugal. ${ }^{11} \mathrm{GfK}$ Switzerland AG, Basel, Switzerland.

Correspondence: Paraskevi Katsaounou, 20 Evergeti Giavasi str, 15341, Athens, Greece.

E-mail: paraskevikatsaounouQggmail.com

ABSTRACT We conducted a large global survey, Still Fighting for Breath, in patients with severe persistent asthma, 10 years after the Fighting for Breath survey to assess the impact of disease on patients' lives and to determine if control and management have changed in recent years.

Data were collected from 1333 adults (aged >18 years) and caregivers of children (aged 6-17 years) with severe persistent asthma from nine countries through an online survey conducted in 2016 by GfK.

A decade after the first survey, our results showed that the impact of severe asthma has not changed significantly and a high proportion of patients with severe asthma remain inadequately controlled. A large discrepancy was observed between the proportion of patients who perceived their asthma to be well controlled (42\%) and the proportion of patients who reported to be well controlled as per the Global Initiative for Asthma (GINA) assessment (6\%). Although most patients perceived their asthma to be controlled, many experienced frequent symptoms that affected their daily lives.

Thus, there is a need for improved management (support and strategies) of patients with severe persistent asthma and improved coordination of efforts that would enable these patients to achieve better disease control.

@ERSpublications

There is a need for improved management of patients with severe persistent asthma to achieve better disease control http://ow.ly/rv5K30mQdGG

Cite this article as: Katsaounou P, Odemyr M, Spranger O, et al. Still Fighting for Breath: a patient survey of the challenges and impact of severe asthma. ERJ Open Res 2018; 4: 00076-2018 [https:// doi.org/10.1183/23120541.00076-2018].

Received: May 292018 | Accepted after revision: Oct 262018

Copyright $\odot$ ERS 2018. This article is open access and distributed under the terms of the Creative Commons Attribution Non-Commercial Licence 4.0. 


\section{Introduction}

Patients with severe asthma experience poorer quality of life and are at an increased risk of exacerbations, hospitalisations and death due to poor disease control [1-3]. Since 2006, achieving good asthma control in these patients has been the cornerstone of the Global Initiative for Asthma (GINA) management strategy aiming to reduce the impact of the disease on patients' daily activities [4, 5]. However, several real-life surveys have shown that asthma control still remains an unmet goal [6].

Previous surveys have reported the major impact of asthma on patients' lives due to the lack of control [7-9]. Many patients with severe persistent asthma were unable to lead regular lives due to a low level of asthma control [10-12]. Notably, approximately half of patients who were clinically adjudged to have severe persistent symptoms considered their asthma to be well controlled [10, 13].

Fighting for Breath was a large-scale survey, conducted by the European Federation of Allergy and Airways Diseases Patients' Associations (EFA) between 2004 and 2005, to understand the impact of severe asthma on patients' lives $[14,15]$. The results indicated that the majority of patients with severe asthma experienced substantial limitations in their life as a consequence of the uncontrolled disease. However, substantial time has passed since such a large-scale survey has been performed, specifically in patients with severe asthma [10, 13-15].

We conducted a large, global, real-life survey, Still Fighting for Breath, aimed to assess the current impact of severe persistent asthma on patients' daily lives and activities. This survey provides a well-timed evaluation to determine whether disease control and management of patients with severe persistent asthma have changed in recent years.

\section{Methods}

Participants

Adult patients aged $>18$ years and caregivers of patients aged 6-17 years (paediatric and adolescent patients) with severe persistent asthma were included in this survey. Participants were enrolled from nine

\section{TABLE 1 Distribution, demographics and disease profile of survey participants by country}

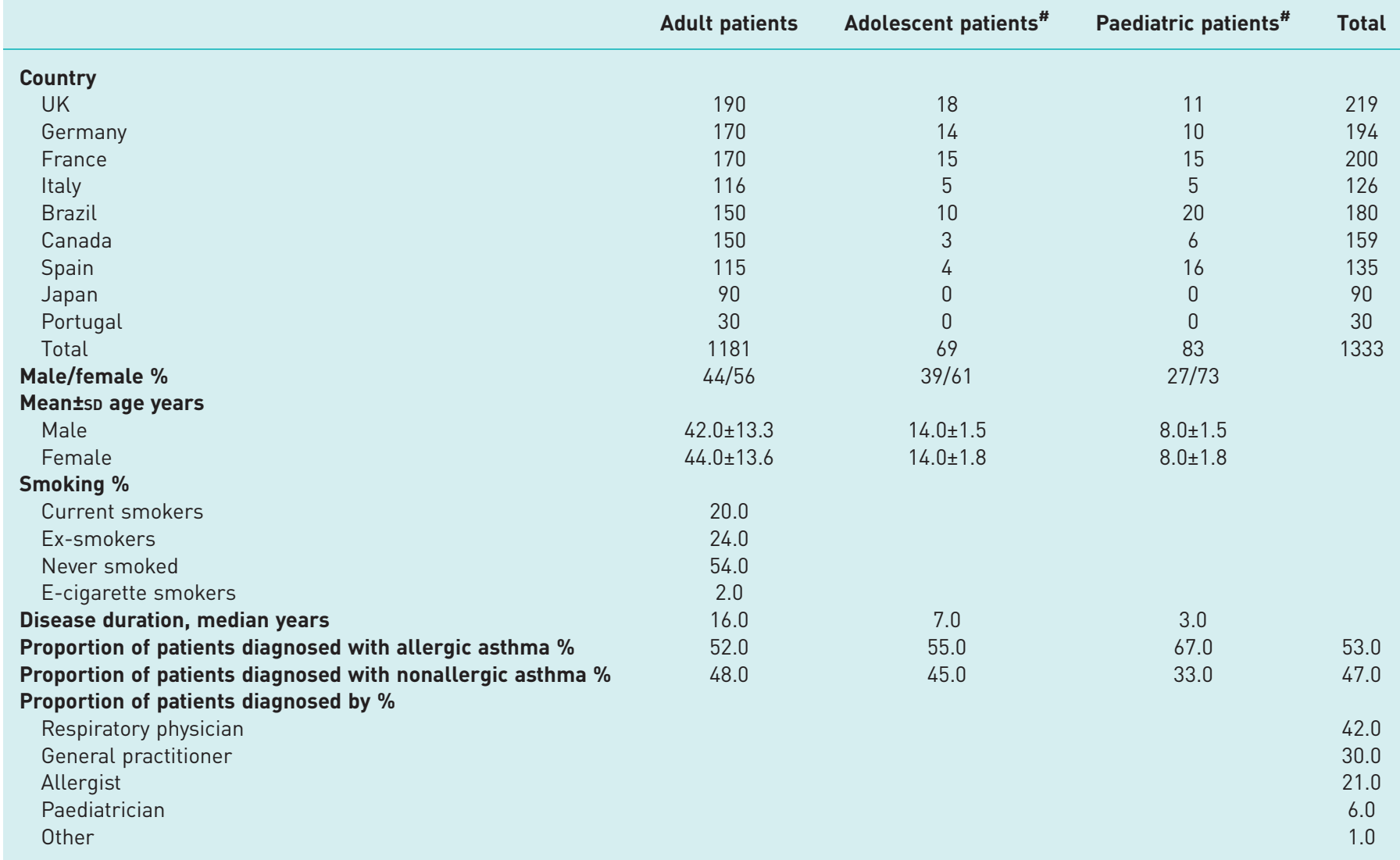

Data are presented as $\mathrm{n}$, unless otherwise stated. ${ }^{\#}$ : data for adolescent and paediatric patients were captured through their caregivers. 


\begin{tabular}{|c|c|c|c|c|}
\hline & Adult & Adolescent ${ }^{\#}$ & Paediatric ${ }^{\#}$ & Total \\
\hline \multicolumn{5}{|l|}{ Prominent words associated with asthma \% } \\
\hline Breathlessness/suffocation & 17.0 & 3.0 & 2.0 & 16.0 \\
\hline Bad/uncomfortable & 6.0 & 7.0 & 5.0 & 6.0 \\
\hline Stress/anxiety & 5.0 & 12.0 & 4.0 & 5.0 \\
\hline Fatigue/tiredness & 4.0 & 0 & 4.0 & 4.0 \\
\hline Respiration & 4.0 & 6.0 & 1.0 & 4.0 \\
\hline Pain/suffering & 3.0 & 7.0 & 4.0 & 4.0 \\
\hline Limited & 3.0 & 6.0 & 1.0 & 3.0 \\
\hline \multicolumn{5}{|l|}{ Symptoms during exacerbations \% } \\
\hline Cough & 59.0 & 62.0 & 69.0 & 60.0 \\
\hline Daytime wheezing & 57.0 & 62.0 & 52.0 & 57.0 \\
\hline Night-time wheezing & 55.0 & 55.0 & 57.0 & 55.0 \\
\hline Persistent shortness of breath & 57.0 & 64.0 & 43.0 & 57.0 \\
\hline Breathlessness while lying down & 55.0 & 51.0 & 43.0 & 54.0 \\
\hline Fatigue & 52.0 & 55.0 & 40.0 & 52.0 \\
\hline \multicolumn{5}{|l|}{ Associated psychological condition \% } \\
\hline Anxiety & 40.1 & 42.0 & 39.0 & 18.0 \\
\hline Depression & 28.2 & 30.0 & 13.0 & 10.0 \\
\hline Other psychological condition & 3.0 & 0 & 0 & 2.0 \\
\hline None of the above & 47.0 & 54.0 & 78.0 & 49.0 \\
\hline \multicolumn{5}{|l|}{ Overall psychological impact \% } \\
\hline Feel limited because of asthma & 47.0 & 42.0 & 25.0 & 45.0 \\
\hline Feel dependent on the medication & 41.0 & 25.0 & 23.0 & 39.0 \\
\hline Feel scared because of potential attack & 34.0 & 33.0 & 27.0 & 33.0 \\
\hline Able to deal with asthma & 30.0 & 36.0 & 34.0 & 31.0 \\
\hline
\end{tabular}

countries (UK, Germany, France, Italy, Spain, Brazil, Canada, Japan and Portugal). Patients and caregivers of paediatric and adolescent patients, mainly identified via databases (consumer panels), were invited to complete the screening questionnaire and were included in this survey only if they met the criteria for severe asthma.

\section{Survey description}

Data were collected using a 20-minute online survey, conducted by GfK on behalf of Novartis, between July 12, 2016 and October 31, 2016. Patients/caregivers completed the questionnaire on asthma control, daily/physical activity, exacerbations, psychological aspects and treatment.

\section{TABLE 3 Distribution of anxiety and depression by country}

\begin{tabular}{|c|c|c|c|c|}
\hline \multirow[t]{2}{*}{ Country } & \multicolumn{2}{|c|}{$\begin{array}{l}\text { Prevalence in severe asthma } \\
\text { patients } \# \%\end{array}$} & \multicolumn{2}{|c|}{$\begin{array}{c}\text { Prevalence in general population } \\
\%\end{array}$} \\
\hline & Anxiety & Depression & Anxiety & Depression \\
\hline Global & 40.1 & 28.2 & 3.6 & 4.4 \\
\hline UK & 39.7 & 35.6 & 4.2 & 4.5 \\
\hline Germany & 36.1 & 40.7 & 5.8 & 5.2 \\
\hline France & 41.5 & 20.5 & 6.2 & 4.8 \\
\hline Italy & 51.6 & 29.4 & 5.0 & 5.1 \\
\hline Brazil & 46.7 & 27.2 & 9.3 & 5.8 \\
\hline Canada & 38.4 & 28.9 & 4.9 & 4.7 \\
\hline Spain & 29.6 & 21.5 & 4.1 & 5.2 \\
\hline Japan & 40.0 & 13.3 & 3.1 & 4.2 \\
\hline Portugal & 30.0 & 16.7 & 4.9 & 5.7 \\
\hline
\end{tabular}


TABLE 4 Impact of asthma on daily activities in patients with severe persistent asthma

\begin{tabular}{|c|c|c|c|c|}
\hline & Adult & Adolescent $^{\#}$ & Paediatric ${ }^{\#}$ & Total \\
\hline \multicolumn{5}{|l|}{ Impact on patients' lives \% } \\
\hline Disruption of activities of daily living & 89.0 & 84.0 & 67.0 & 88.0 \\
\hline Disruption of physical activities & 84.0 & 90.0 & 89.0 & 84.0 \\
\hline Disruption of sleep & & & & 97.0 \\
\hline Negative impact on self-esteem & 53.0 & 45.0 & 32.0 & 51.0 \\
\hline Negative impact on professional life & 58.0 & \multicolumn{2}{|c|}{$36.0^{9}$} & 55.0 \\
\hline \multicolumn{5}{|l|}{ Wellbeing assessment $\%$} \\
\hline Felt cheerful and in good spirits & 4.0 & \multicolumn{2}{|c|}{$3.0^{\pi}$} & 4.0 \\
\hline Felt calm and relaxed & 5.0 & \multicolumn{2}{|c|}{$3.0^{\pi}$} & 5.0 \\
\hline Felt active and vigorous & 11.0 & \multicolumn{2}{|c|}{$2.0^{\pi}$} & 10.0 \\
\hline Woke up feeling fresh and relaxed & 15.0 & \multicolumn{2}{|c|}{$9.0^{\pi}$} & 14.0 \\
\hline Daily life has been filled with things that interest me & 6.0 & \multicolumn{2}{|c|}{$5.0^{\text {ก }}$} & 6.0 \\
\hline
\end{tabular}

\section{Definition and assessment of severity}

Experiencing severe symptoms throughout the previous year was considered as severe persistent asthma. Severity of disease was self-reported by patients based on the question: "Thinking about the severity of your/your child's asthma, what did your doctor tell you the last time you talked about severity?" This answer was further validated using the GINA questionnaire.

\section{Assessment of asthma control as per GINA guidelines}

Asthma control assessment according to GINA is based on four questions: In the past 4 weeks, has the patient had (yes/no): 1) ...daytime symptoms more than twice a week?; 2) ....any night waking due to

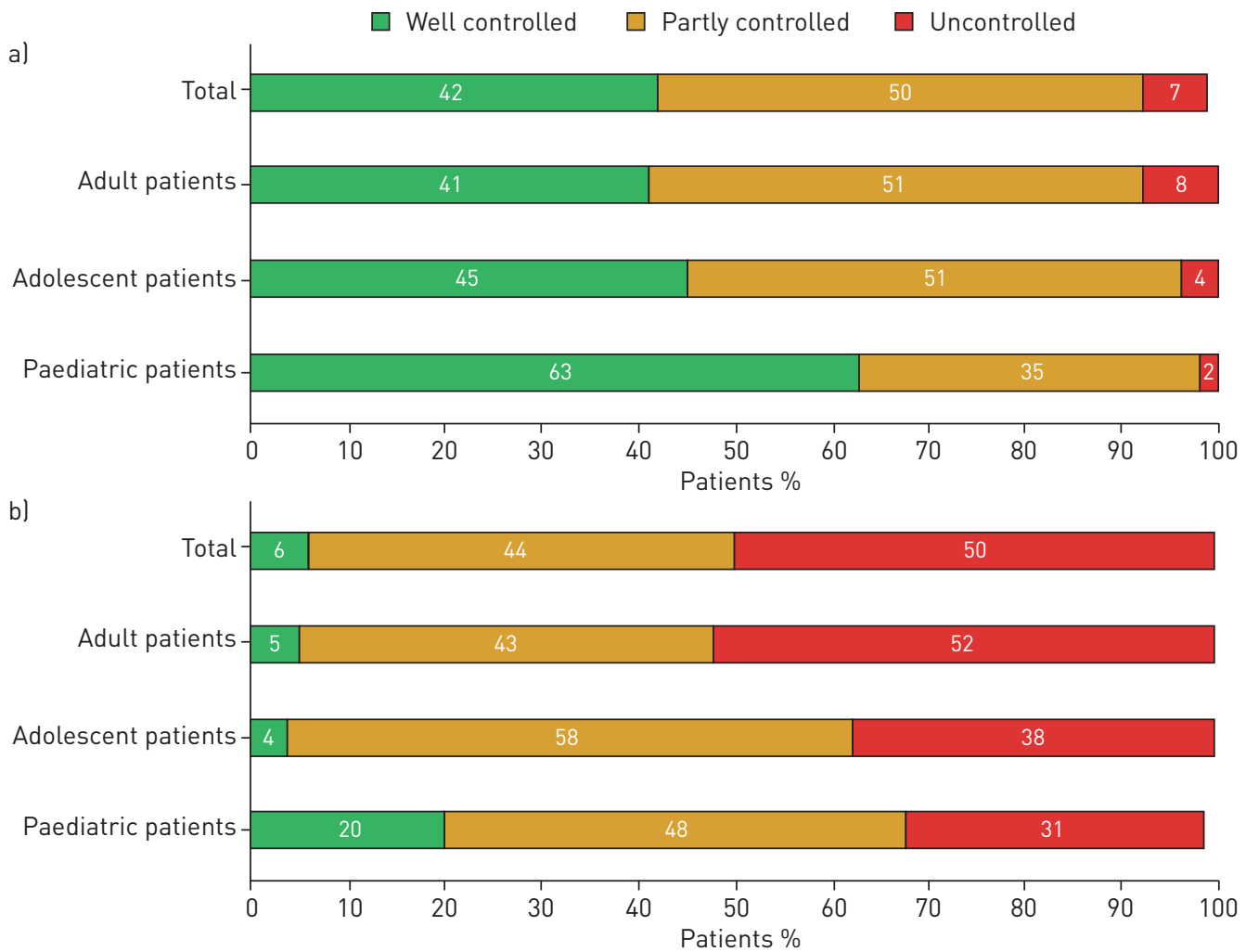

FIGURE 1 Level of control a) as perceived by patients, and b) as per the Global Initiative for Asthma control questionnaire. Rounding differences may be observed for these data. 
a)

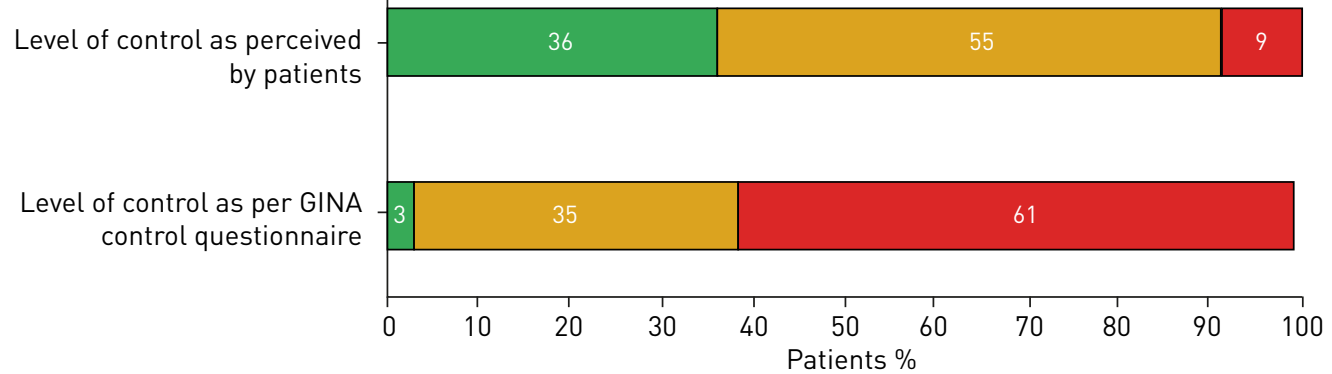

b)

Level of control as perceived by patients

Level of control as per GINA control questionnaire

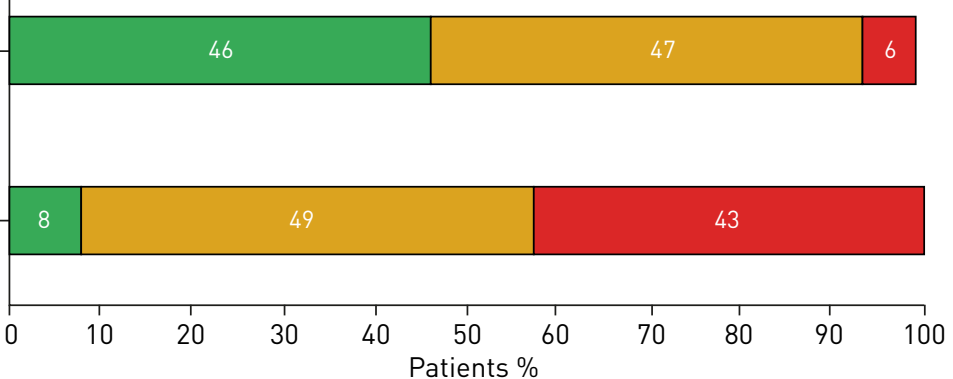

FIGURE 2 Level of control in a) high oral corticosteroid users and b) low oral corticosteroid users. Rounding differences may be observed for these data. GINA: Global Initiative for Asthma.

asthma?; 3) ...the need for reliever medication more than twice a week?; and 4) ....any activity limitations due to asthma? Patients experiencing none of the above symptoms were categorised as well controlled; patients experiencing one or two of the symptoms were considered as partly controlled and those experiencing three or four of the symptoms were considered to be uncontrolled patients.

\section{Results}

Participants

A total of 1333 patients were surveyed, 1181 of whom were adults and 152 were caregivers of paediatric and adolescent patients. Overall, 53\% of the total survey population was diagnosed with allergic asthma, reported based on patient knowledge. The country-wise patient distribution, demographics and disease profile are shown in table 1.

\section{Clinical and psychological impact}

In the previous year, $73 \%$ of the total population experienced at least one exacerbation, of these, $34 \%$ experienced more than two exacerbations that required emergency treatment (intervention by a healthcare professional (HCP), emergency room visit, ambulance use, or physician at home). Overall, $51 \%$ of patients

\section{TABLE 5 Comparison of Fighting for Breath and Still Fighting for Breath survey results}

\begin{tabular}{lcc} 
Parameter & Fighting for Breath survey & Still Fighting for Breath survey \\
\hline Year of study & 2005 & 2016 \\
Total population n & 1300 & 1333 \\
Disturbed sleep \% & 42.0 (about once a week) \\
& 24.0 (more than once week) & 97.0 \\
Wheezing \% & 42.0 (about once a week) & 57.0 \\
& 24.0 (more than once week) & 32.0 \\
Missed going out with friends \% & 38.0 & 24.0 (I worry that I will lose my job) \\
Missed out job opportunities \% & 21.0 & 39.0 \\
Missed holidays \% & 28.0 & 69.0 \\
Physical activities \% & 84.0 & 20.0 \\
Missed joining in at school or at college \% & 14.0 & 40.0 \\
Having pets \% & 49.0 &
\end{tabular}


who had an exacerbation that required emergency treatment clinically recovered within $24 \mathrm{~h}$, although $13 \%$ required $\geqslant 1$ week to recover. However, emotional/psychological recovery took longer, with $39 \%$ of patients recovering within $24 \mathrm{~h}$, while $21 \%$ needed $\geqslant 1$ week to recover. Of the total population, $50 \%$ reported having been clinically diagnosed with a psychological condition by an HCP. A detailed description of the impact of asthma on psychological wellbeing and daily activities is given in tables 2-4.

\section{Impact on daily and professional lives}

The majority of patients reported disruption of "physical activities" (84\%), "activities of daily living" (88\%) and "sleep" (97\%). Of the total population, $58 \%$ of adult patients and $36 \%$ of caregivers perceived asthma to be negatively affecting their professional working lives, with the main factors being "not able to concentrate", "taking time off due to asthma", and "not being able to be fully productive".

\section{Asthma control}

In the total population, a large discrepancy was observed between the proportion of patients who perceived their asthma to be well controlled (42\%) and the proportion of patients who were reported as well controlled as per GINA assessment (6\%); similar discrepancies were also observed in the adult, adolescent and paediatric subpopulations (figure 1).

Most patients (91\%) who used oral corticosteroids (OCSs) for $\geqslant 14$ days (high OCS users) perceived their disease to be either partly controlled or well controlled; however, only $38 \%$ of these patients were partially or well controlled as per GINA assessment. There was a strong disconnect between the patient's perception and GINA assessment of disease control in both low and high OCS users (figure 2).

\section{Treatment}

Of the total population, 58\% of patients received short-acting rescue medication on top of the maintenance treatment. The mean duration of OCS use was reported to be 20 days in the last 6 months, while $63 \%$ of patients surveyed used OCSs on fewer than 14 days in the last 6 months (low OCS users).

\section{Discussion}

The observed impact of severe asthma on patients included in our survey was similar to that reported in the Fighting for Breath survey conducted in 2005 [14, 15]. Comparison of key parameters between the

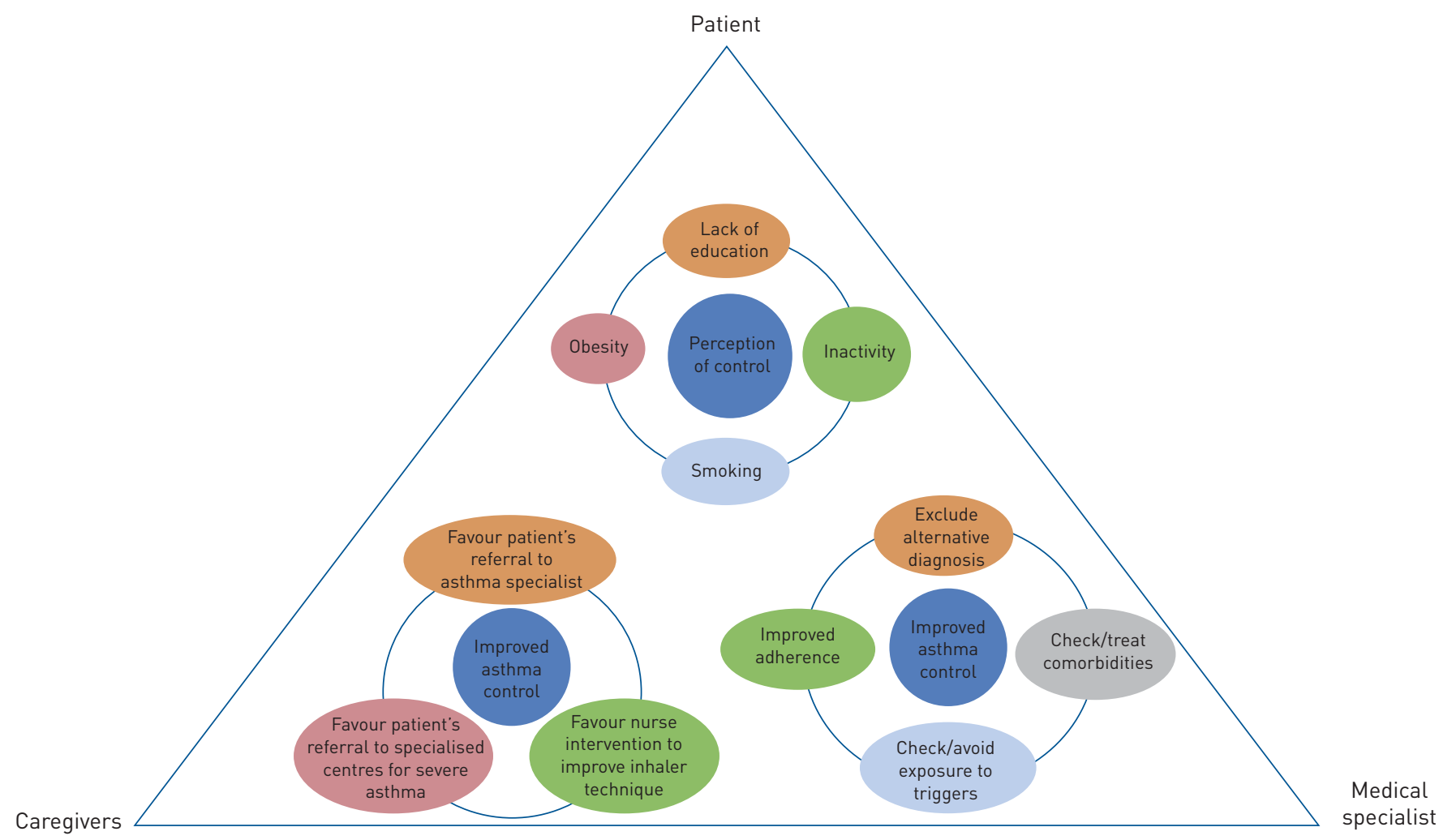

FIGURE 3 Holistic approach for severe asthma management. 
Fighting for Breath and Still Fighting for Breath surveys is presented in table 5. It should be noted that a comparison in terms of the extent of asthma control between the two surveys may not be possible as assessment of control was not included in the GINA guidelines when the previous survey was performed.

However, our results suggest that most patients with severe asthma still experience a lack of control and poor quality of life. Our survey also shows that there is a significant disconnect between guideline-defined asthma control and patient-perceived asthma control in patients with severe asthma. This was reflected in the large discrepancy observed between the proportion of patients who perceived their asthma to be well controlled (42\%) and the proportion of patients who were reported as well controlled as per GINA assessment (6\%). As per our survey, only $58 \%$ of patients reported that they were taking short-acting $\beta$-agonists (SABAs) on top of the maintenance therapy. However, we would expect that all patients used SABA as a reliever medication. We believe that the misperception of asthma control may have led to the nonusage of SABAs by all patients, considering that from the $42 \%$ that believed their asthma was well controlled, only $6 \%$ were well controlled as per the GINA assessment. These $42 \%$ were not using SABAs as reliever medication. However, due to the design of the survey it cannot be determined if these patients were also not well educated, were nonadherent or were using additional long-acting muscarinic antagonists (LAMAs) and/or monoclonal antibodies instead of SABAs. There are reports about asthmatics using biologics showing a reduction in SABA use [16].

Several factors may be responsible for this lack of asthma control, including inadequate or non-personalised disease-management support for individuals, inappropriate pharmacological treatment, nonadherence or inadequate adherence to medication, poor inhaler technique and poor adherence to the overall asthma management plan, and lack of referral to a specialist or poor diagnosis/asthma management by the HCP $[4,17,18]$.

In the Fighting for Breath survey, patients were asked to indicate the possible reasons for their poor quality of life. The three major reasons reported were exposure to passive smoking, lack of treatment by a specialist and absence of new treatments $[14,15]$. Consequently, in the past decade, various steps have been taken to improve the quality of life of asthma patients. These include: implementation of laws banning smoking in public spaces $[19,20]$, introducing new treatments such as monoclonal antibody-based therapies [21], and guideline-recommended new indication of LAMAs [22] for the effective treatment of patients with asthma. After a decade, our results show that patients with asthma still have a poor quality of life and experience symptoms that affect their daily lives. Though it should be noted that there is no information whether patients included in our survey were eligible for (or on), monoclonal antibody-based therapies.

Proper perception of control is associated with improved asthma-related health status as well as decreased prospective risk for severe exacerbations [23]. Patients' perception of asthma control can influence both adherence to treatment and care by physicians; a better understanding of disease and disease control is therefore important in order to achieve optimal treatment outcomes and improve asthma management [24, 25]. Poor perception of symptoms may lead to incorrect or under-treatment resulting in increased morbidity and mortality from asthma [26]. Various factors have been associated with this poor perception of control. These include smoking $[27,28]$, psychological factors such as anxiety and depression (common in people with severe asthma) [29, 30], obesity, physical inactivity [31], and low educational status. There have also been efforts to further educate HCPs to take informed decisions on when to refer patients with severe asthma to specialist centres and to educate patients on ways to understand and recognise their disease condition and symptom control $[32,33]$. However, the results of our survey show that patients with severe asthma still have a poor perception of symptom control leading to poor quality of life, but if we are to empower patients this cannot be placed as the fault of the individual. Although a majority of patients perceived their asthma to be controlled, many still experienced frequent symptoms that affected their daily lives, and $73 \%$ of patients reported exacerbations that required HCP intervention. Furthermore, proportion of population suffering from psychological condition in this survey (anxiety, 40.1\%; depression, 28\%) was substantially higher than observed in general population (anxiety, 3.6\%; depression, 4.4\%) [34] (table 3). This suggests that a high proportion of patients "had a poor perception of their asthma" and did not recognise the extent of their symptoms due to asthma, thus tending to overestimate their disease control.

Hence, we propose to include perception of control in patients with asthma as a crucial component of disease assessment and management in order to facilitate improving control in these patients.

The current survey results also highlight that depression and anxiety due to asthma maybe important conditions that are either not revealed or are underestimated. Namely, half of the population surveyed here reported being diagnosed with a psychological condition, with the majority of the patients suffering from anxiety and depression, which is similar to the findings reported previously $[35,36]$. 
There are some limitations of this survey: data presented herein were obtained via an online survey; hence, the data were self-reported by patients or their caregivers and were not clinically verified and thus, inaccurate responses due to poor recall cannot be excluded. Moreover, it is difficult to precisely predict the actual factors behind participant responses. Data for minor patients were reported by their caregivers; these responses may not be reflective of the actual situation, especially the smoking status among these patients. The definition of severe asthma was based on patient-reported symptom history in the past year and was not as definitive as provided by the guidelines.

Overall, our survey highlights that a substantial gap remains between guideline-defined and patientperceived asthma control in patients with severe asthma. Over a decade after the Fighting for Breath survey was conducted, little seems to have changed in terms of the quality of life of patients with severe asthma. Severe asthma patients still live with uncontrolled asthma, experience exacerbations, suffer from psychological symptoms and have an unacceptable level of quality of life. Moreover, patients' perception of "asthma control", and their expectations of "good asthma control" appear alarmingly low. This is despite a decade of increased research and resource provision in severe asthma, multiple changes to guidelines and new advancements in pharmacological intervention. Severe asthma patients are Still Fighting for Breath and we advocate a thorough reconsideration of our approach to the management of severe asthma (figure 3 ). If no action is taken, it is unlikely that the next 10 years will see any substantial change in the quality of lives of severe asthma patients in all age groups. Our proposals are: to develop tools to assess asthma symptom perception and to subsequently include such a measure in the routine assessment of patients with asthma; and to reinforce the education of asthma patients through HCPs and patient organisations.

\section{Conclusions}

This large-scale global survey showed that severe persistent asthma has a major impact on patients, affecting their daily and professional activities, and having a negative impact on their psychological condition. Most patients with severe asthma remain inadequately controlled. In addition, there is a strong disconnect between guideline-defined and patient-perceived asthma control. Thus, there is a need for improved management (support and strategies) of patients with severe persistent asthma and better coordination of efforts including those aimed at enhancing asthma education, assessing perception of control, patient-physician interaction, guideline implementation, treatment adherence and involvement of patient organisations. Implementation of these measures would go some way to enabling these patients to achieve better disease control.

Acknowledgements: The authors thank Jisha John and Rahul Lad of Novartis, Hyderabad, India for providing medical writing support/editorial support, which was funded by Novartis, in accordance with Good Publication Practice (GPP3) guidelines.

Conflict of interest: P. Katsaounou reports an ERS fellowship at Novartis, during the conduct of the study; and personal fees from GSK, Chiesi, Menarini, Pfizer, Boehringer Ingelheim, outside the submitted work. M. Odemyr reports grants from AirLiquide Healthcare, grants from ALK Abellò, grants from AstraZeneca, grants from Boehringer Ingelheim, grants from Chiesi, grants from GSK, grants from Novartis, grants from TEVA, grants from Regeneron, grants from SigAirHandling, grants from Stallergenes, and grants from Sanofi Genzyme, outside the submitted work; and is Vice President of the Swedish Asthma and Allergy Association, who receives no funds from companies in the pharmaceutical sector. M. Odemyr is also President of the European Federation of Allergy and Airways Diseases Patients' Associations (EFA) who receives unrestricted core and project funding from corporate sources, in addition to membership fees and EU project funding. M. Odemyr is a volunteer and receives no remuneration. EFA develops sustainable corporate partnership with funders where both remain independent and fosters transparency. The EFA Code of Ethics and Framework for Sustainable Partnership are available at www.efanet.org as well as the annual accounts 2017 (www.efanet.org/annual-report/2017/financials/transparency-and-acknowledgements). O. Spranger has nothing to disclose. M. Hyland reports grants and personal fees from Novartis, grants from AstraZenneca, and personal fees from GSK, outside the submitted work. C. Kroegel has nothing to disclose. R. Gore reports nonfinancial support from Novartis UK, outside the submitted work. F. Menzella has nothing to disclose. M. Morais-Almeida has nothing to disclose. M. Gasser reports that Novartis funded the market research survey conducted by GfK Switzerland, during the conduct of the study. I. Kasujee is an employee of Novartis Pharma AG. C. Domingo Ribas reports personal fees from Novartis, personal fees from GSK, personal fees from Sanofi, from AstraZeneca, from ALK, and personal fees and other support from Menarini, from Orion, outside the submitted work. L. Garcia Conde is an employee of Novartis Pharma AG.

Support statement: The study was funded by Novartis Pharma AG, Basel, Switzerland. Funding information for this article has been deposited with the Crossref Funder Registry.

\section{References}

1 Peters SP, Ferguson G, Deniz Y, et al. Uncontrolled asthma: a review of the prevalence, disease burden and options for treatment. Respir Med 2006; 100: 1139-1151.

2 FitzGerald JM, Boulet LP, McIvor RA, et al. Asthma control in Canada remains suboptimal: the Reality of Asthma Control (TRAC) study. Can Respir J 2006; 13: 253-259. 

general practice. Eur Respir J 2008; 31: 320-325.

4 Global Strategy for Asthma Management and Prevention. Global Initiative for Asthma. 2016. https:/ginasthma. org/wp-content/uploads/2016/04/wms-GINA-2016-main-report-final.pdf

5 Global Strategy for Asthma Management and Prevention. Global Initiative for Asthma. 2006.

6 Papaioannou AI, Kostikas K, Zervas E, et al. Control of asthma in real life: still a valuable goal? Eur Respir Rev 2015; 24: 361-369.

7 Price D, Fletcher M, van der Molen T. Asthma control and management in 8000 European patients: the REcognise Asthma and LInk to Symptoms and Experience (REALISE) survey. NPJ Prim Care Respir Med 2014; 24: 14009 .

8 Fletcher M, Hiles D. Continuing discrepancy between patient perception of asthma control and real-world symptoms: a quantitative online survey of 1,083 adults with asthma from the UK. Prim Care Respir J 2013; 22: 431-438.

9 Beharry S, Gidla D, Maharaj A, et al. Reality and understanding of asthma control. Chron Respir Dis 2015; 12: 340-346.

10 Rabe KF, Vermeire PA, Soriano JB, et al. Clinical management of asthma in 1999: the Asthma Insights and Reality in Europe (AIRE) study. Eur Respir J 2000; 16: 802-807.

11 Canonica GW, Baena-Cagnani CE, Blaiss MS, et al. Unmet needs in asthma: Global Asthma Physician and Patient (GAPP) Survey: global adult findings. Allergy 2007; 62: 668-674.

12 National Asthma Campaign, Asthma UK: Living on the Knife Edge. 2004

13 Lai CK, De Guia TS, Kim YY, et al. Asthma control in the Asia-Pacific region: the Asthma Insights and Reality in Asia-Pacific Study. J Allergy Clin Immunol 2003; 111: 263-268.

14 Fighting for Breath. European Federation of Allergy and Airway Diseases Patients Association, 2004. www.efanet. org/images/2012/07/Fighting_For_Breath1.pdf Date last accessed: December 10, 2018.

15 Dockrell M, Partridge MR, Valovirta E. The limitations of severe asthma: the results of a European survey. Allergy 2007; 62: 134-141.

16 Ozgur ES, Ozge C, Ilvan A, et al. Assessment of long-term omalizumab treatment in patients with severe allergic asthma long-term omalizumab treatment in severe asthma. J Asthma 2013; 50: 687-694.

17 Magnoni MS, Latorre M, Bettoncelli G, et al. Asthma control in primary care: the results of an observational cross-sectional study in Italy and Spain. World Allergy Organ J 2017; 10: 13.

18 NRAD. Royal College of Physicians. Why Asthma Still Kills. The National Review of Asthma Deaths (NRAD) Confidential Enquiry Report. 2014.

19 Areias A, Duarte J, Figueiredo J, et al. Asthma and the new anti-smoking legislation. What has changed? Rev Port Pneumol 2009; 15: 27-42.

20 Centre for Public Impact. Smoking ban in England and Wales 2016. www.centreforpublicimpact.org/case-study/ smoking-ban-england-and-wales/ Date last accessed: August 20, 2018.

21 Darveaux J, Busse WW. Biologics in asthma-the next step toward personalized treatment. J Allergy Clin Immunol Pract 2015; 3: 152-160.

22 McIvor ER, McIvor RA. The evolving role of tiotropium in asthma. J Asthma Allergy 2017; 10: $231-236$.

23 Calfee CS, Katz PP, Yelin EH, et al. The influence of perceived control of asthma on health outcomes. Chest 2006; 130: $1312-1318$.

24 Horne R, Price D, Cleland J, et al. Can asthma control be improved by understanding the patient's perspective? BMC Pulm Med 2007; 7: 8.

25 Bereznicki BJ, Chapman MP, Bereznicki LRE. Factors associated with overestimation of asthma control: a cross-sectional study in Australia. J Asthma 2017; 54: 439-446.

26 Manning HL, Schwartzstein RM. Respiratory sensations in asthma: physiological and clinical implications. J Asthma 2001; 38: 447-460.

27 Massasso DH, Salome CM, King GG, et al. Perception of bronchodilation in subjects with asthma and smokers with airflow limitation. Respirology 1999; 4: 117-124.

28 Boulet LP, FitzGerald JM, McIvor RA, et al. Influence of current or former smoking on asthma management and control. Can Respir J 2008; 15: 275-279.

29 Yellowlees PM, Ruffin RE. Psychological defenses and coping styles in patients following a life-threatening attack of asthma. Chest 1989; 95: 1298-1303.

30 Demoly P, Paggiaro P, Plaza V, et al. Prevalence of asthma control among adults in France, Germany, Italy, Spain and the UK. Eur Respir Rev 2009; 18: 105-112.

31 Mdel C V, Picado C, Herraez L, et al. Factors associated with severe uncontrolled asthma and the perception of control by physicians and patients. Arch Bronconeumol 2014; 50: 384-391.

32 Urek MC, Tudoric N, Plavec D, et al. Effect of educational programs on asthma control and quality of life in adult asthma patients. Patient Educ Couns 2005; 58: 47-54.

33 Blackstien-Hirsch P, Anderson G, Cicutto L, et al. Implementing continuing education strategies for family physicians to enhance asthma patients' quality of life. J Asthma 2000; 37: 247-257.

34 WHO. Depression and Other Common Mental Disorders, Global Health Estimates. Geneva, World Health Organization, 2017.

35 Vieira AA, Santoro IL, Dracoulakis S, et al. Anxiety and depression in asthma patients: impact on asthma control. J Bras Pneumol 2011; 37: 13-18.

36 Leao LL, Zhang L, Sousa PL, et al. High prevalence of depression amongst mothers of children with asthma. J Asthma 2009; 46: 388-391. 